\title{
Editorial
}

\section{0 perenemente transitório em saúde mental}

Quando o escritor mineiro Guimarães Rosa afirmava ser o amor um antídoto para combater a doença ${ }^{1}$, ou melhor, alçando o amor como um sentimento capaz de promover a saúde, de certo não se referia apenas ao amor romântico e burguês que, muitas vezes, insiste em ser aclamado como uma cura para aqueles que sofrem. Antes disso, esse amor estaria relacionado a um sentimento de compaixão pelo outro, de respeito, de interesse pelo outro, de possibilidade de diálogo em busca de compreensão. Quem compreendesse poderia, então, ser empático, colocarse no lugar do outro e, com isso, permitir que a loucura do viver descansasse, desse uma trégua, restando a sensação de saúde. Essa saúde, quase um sinônimo de descanso, de interstício, seria interrompida pelo nosso modo contemporâneo de vida, acelerado, em desalinho, buscando realizações que, muitas vezes, não se referem a desejos próprios, mas a expectativas sociais que, frequentemente, promovem sofrimento quando não podem ser atendidas.

Vivemos em tempos de um mal-estar quase perene que atravessa relações, modos de ser, de existir e também de cuidar do outro ${ }^{2}$. Esse chamado mal-estar contemporâneo vem sendo discutido por diferentes interlocutores, ora por filósofos, psicólogos, psiquiatras e por demais especialistas, ora pelo conhecimento popular, como nas redes sociais. Em uma arena discursiva na qual esses saberes por vezes se chocam, por vezes se alinham, é premente que possamos lançar um olhar mais atento e cuidadoso ao fenômeno que se agiganta em nossa sociedade: a saúde mental. Em tempos de excessos, inclusive terminológicos, expressões ganham o espaço discursivo e emergem como deflagradoras de processos internos e também sociais que devem ser debatidos por todos: adoecimento psíquico, sofrimento psíquico, sofrimento mental, loucura, equilíbrio emocional, condições emocionais... saúde mental, apenas para citar alguns mais recorrentes.

Por que, quase no início da terceira década do século XXI, o termo saúde mental vem sendo cada vez mais evocado, tanto nos meios formais como informais? Embora alguns estudos retratem de modo sistemático a construção da história da saúde mental ${ }^{3,4}$ deve-se sinalizar, na contemporaneidade, que o termo saúde mental tem deixado de ser uma expressão típica dos antigos hospitais psiquiátricos e passou a conviver com leigos e não leigos em rodas de conversas, debates acalorados na internet, costurando toda e qualquer formação de cursos no campo da saúde. Desse modo, torna-se um termo onipresente, mas que não chega a ser consumido como algo que está saturado, pelo contrário: acerca desse conceito muito ainda tem sido pensado e produzido e, nos tempos atuais, transmitido ${ }^{3}$. A saúde mental não passa a ser, propriamente, um termo "da moda", mas emerge como algo necessário, sendo premente a tarefa de nossa sociedade em assumir a importância e complexidade em torno dessa expressão que tão bem tem marcado nossas últimas décadas. Vivemos, pois, um momento histórico no qual essa expressão tem se corporificado no modo como nos relacionamos, como produzimos, como adoecemos e como existimos.

O constructo saúde mental já passou por algumas reformulações desde sua clássica definição que pressupunha um modelo estável de retorno à homeostase, caracterizando o "completo bem-estar" bio-psico-social5. A herança presente neste padrão de atenção é o modelo biomédico, predominante no início das profissões que envolvem a saúde do ser humano, que entoava os moldes cartesianos de replicabilidade e medidas adequadas da saúde física. ${ }^{6}$ As necessidades de cuidado vêm buscando alargar fronteiras e olhares diante da transitoriedade que caracteriza o viver e sua maneira humana com medidas de saúde singulares a cada vivente. A pesquisa clínica converge nesta mudança de paradigma e se aplica também buscando quebrar preconceitos em saúde mental e estereótipos históricos. A crise na saúde e a mudança dos saberes se mostram constantes no modo de cuidar contemporâneo.

A mudança de paradigma de cuidado à saúde, com o advento do modelo psicossocial, vem incrementando variáveis nos vértices da saúde pública, implicando questionamentos à estabilidade humana e seus prescritivos de saúde, diante de altos índices de tratamentos ineficazes e muitas vezes iatrogênicos que compõem cerca de metade das entradas nas triagens 
de saúde e suas demandas na atenção primária7. Dentre os dados da Organização Mundial de Saúde incluiu-se a depressão e a ansiedade, como os transtornos com mais alta incidência na população geral, contexto na qual $4,4 \%$ da população mundial sofre com depressão, enquanto $3,6 \%$ sofre com transtornos de ansiedade, sendo que a depressão sozinha é capaz de mais desfechos disfuncionais e mortes por suicídio ${ }^{7}$. Enfocados na eliminação do sintoma e no reestabelecimento dos sintomas emergentes, para a extinção do problema, a cada novo sintoma se desequilibra a Existência. 0 movimento que segue com o aumentado fluxo de demandas é o do paciente "porta-dor" de síndromes agudas que se tornam crônicas, comumente tratadas como morbidades ou co-morbidades em saúde mental, e que sofrem a medicalização ofertada e disponível no sistema de saúde.

As práticas em diferentes ciências da saúde buscaram questionar o modelo curativo, que não responde eficazmente por pacientes reincidentes em diferentes especialidades médicas, fazendo circular suas queixas e tornando o sistema de saúde alargado em demandas sem resolutividade em seus casos, e ainda, aumentando a circulação em profissionais especialistas para acolher condições de "saúde mental", que culminam em reforçar o modelo cartesiano e protocolar de controle e remissão da psicopatologia instaurada.

A psicopatologia, em diferentes abordagens terapêuticas, reflete o saber-fazer com as populações e o ciclo vital, no acolhimento da Existência de seus "porta-dores" do eixo saúdedoença, em um fluxo contínuo de compreensão dos modos de descrever as vivências doloridas, as restrições e ainda o modo de estabelecer sua medida existencial na da atualidade, de maneira descritiva sobre seus modos de ser e estar no mundo, caracterizando um psicodiagnóstico que evita classificações estáticas ${ }^{8}$.

Mas, todo "porta-dor" carrega o estigma do adoecer, da patologia psíquica, das limitações cognitivas e sociais ao adentrar o cenário da saúde mental. Neste ponto, a Psicologia estabelece um lugar redundante de especialista, por também não conseguir sozinha adentrar o todo de cada patologia, precisando fazer uso da colaboração de saberes da equipe multidisciplinar, seja para excluir causas orgânicas do acometimento mental e até verificar interações medicamentosas. Questionamos, então: Qual o lugar da saúde mental?

Atualmente, temos um deslocamento do conceito de saúde, influenciado pelas buscas estéticas da população e dos serviços de saúde ofertados na esperança de manter uma outra homeostase humana ilusória: negar o tédio e a própria finitude, trazendo uma gama de procedimentos estéticos e restauradores da imagem jovem e saudável, beirando uma compulsão pelo hedonismo ao corpo, havendo novamente o recorte corpo e mente. Questionamos, aqui: Qual a natureza e ideologia de cuidado destes serviços, instituições e profissionais que compõem a negação da temporalidade? Enquanto pesquisadores e profissionais do campo da saúde mental, como podemos nos localizar nessa territorialidade contemporânea cada vez menos densa?

Com o advento da chamada pós-modernidade, notamos uma busca efusiva pelo tempo bem vivido, alongado e prazeroso, quase que uma eternização do corpo saudável e exclusão dos revezes comuns da existência e suas mazelas incontroláveis. Assim, surge a questão, ainda sem resposta: Quais problemas se mostram provenientes de um horizonte histórico prescritivo do "mais viver" versus "melhor viver"? E, ainda, o que explicaria tamanha compulsão pelo prazer que precisa ser assertivo para o seu sucesso?

Ao pensar a Existência contemporânea na ótica da saúde mental, questionamos ainda: Quais vértices profissionais ou multiprofissionais predominam no olhar? Haveria um segundo olhar frente às estatísticas? Quais as doenças epocais predominantes na população e sua incidência? Qual a métrica de saúde mental na atualidade e seus marcadores dos índices de normalidade, que outrora tinha seus parâmetros definidos descritivamente no manual do DSMIV? 0 que muda, o que se perde e o que se ganha a cada novo padrão normativo que criamos em busca do que ponderamos ser a saúde mental?

Assistimos, cotidianamente, à busca incessante pela perfeição, medicalização e extinção de possíveis desajustes da saúde: agudos, crônicos ou qualquer outra "des-ordem" que aponte para o sofrimento humano, marcadas pelo tempo da pressa na resolutividade e estética como a marca de um tempo pós-moderno, um tempo que não acolhe desvios, um tempo prescritivo das normas do bem-estar e do bem-viver, com receitas e conselhos positivos e que rejeita qualquer 
anunciação de fracasso. Um tempo que não permite os interstícios ou, usando a célebre frase de Guimarães Rosa que abre este texto, o descanso na loucura ${ }^{1}$. Se não se pode "descansar na loucura" em tempos de excessos e atravessamentos temporais, tampouco pode ser possível descansar na saúde.

As mídias veiculadas e grupos virtuais de apoio, juntamente com o atendimento virtual, trazem profissionais que não podem perder tempo de consulta ou envolvimento com a história do paciente, e assim se apressam para corresponder às demandas da população que, evita enfocar as queixas da vida sofrida e adoecida, que apontam, sobretudo, para a falta de sentido desta, que não se encontra com os prescritivos da modernidade.

Não se pode perder tempo ao falar. Não se pode perder tempo ao ouvir. Prescrever e medicar são as ações mais urgentes que oferecem uma falsa percepção de eficiência, pois nem sempre estamos acessando, de fato, o sujeito em sofrimento. E também as modernas tecnologias de comunicação e informação deixam de funcionar de modo adequado, ao que se propõem e contribuem para o fortalecimento de um modo de se relacionar cada vez mais distanciado, rápido e comprometido com um tempo escasso. A tecnologia que nos permitiria uma melhor comunicação passa a ser algo que torna mais ágil a transmissão da informação, o que é muito importante, mas que não se corporifica em atitudes que, de fato, possibilitam a comunicação, o contato, o compartilhamento real do "com-viver".

O sentido do adoecer precisa ser narrado e servir de termômetro que acusa a necessidade de cuidados e não em extinguir rapidamente a dor ou o sintoma. É preciso escuta genuína, compreender a narrativa desta dor no itinerário de cuidados destes pacientes em diferentes contextos de saúde que apontam também como fenômeno que se revela, ouvir sua história com os sintomas e suas nuances que acometem a vida de seu acontecer humano, acolhendo o sofrimento já como o primeiro sintoma e os demais como partes desse processo de cuidado. Não é possível compreender o outro, este que clama por ajuda, sem a paciência que envolve o cuidar, o apoiar e acompanhar no modo de acolhimento, do paciente, da família, da equipe e da própria comunidade.

Este número especial vem em resposta aos problemas da atualidade, situado como uma contrapartida ao modelo cartesiano ofertado, trazendo um modelo artesanal, construído em diversas mãos, vários tecidos de uma trama ora clínica e ora institucional, em que se entrelaçam na busca de sustentar a dialética por respostas e questionamentos na saúde mental, por possuir um modo de ser único e personalizado a cada necessidade da população, respeitando o ciclo vital e suas diferentes temporalidades que clamam por um cuidado atencioso às necessidades biopsicossociais e espirituais, próprias da saúde integrativa.

A pesquisa eleva a ciência enquanto atualização das práticas psicológicas. Saberes e fazeres se constroem e descontroem em um movimento dialético diante das necessidades emergentes em um mundo tão transitório sobre constructos e definições sobre o conceito de saúde mental, que nos resta situá-lo no encontro com o outro e também sobre aquele que sente e cuida desta saúde: o próprio profissional humano e capacitado, buscando um equilíbrio entre seu crescer profissionalmente e contribuir com o cuidado na saúde mental da própria população, compreendendo que a soma de saberes favorece e não limita o profissional. A pesquisa cumpre a função informativa, mas principalmente busca tirar da invisibilidade as populações à margem, ditas "comprometidas emocionalmente", vulneráveis e, por vezes, rotuladas como "desviantes" às normas da ciência.

Os diferentes contextos desenvolvimentais e os diferentes sentidos sobre saúde mental narrados nos artigos que compõem o presente número não se sustentam no fortalecimento de um mundo de excessos, mas apresentam-se como possibilidades de leituras que se alinham a um discurso que clama pela complexidade, pela pluralidade e, mais do que isso, por uma saúde mental que esteja comprometida com a busca do que promova o bem-estar, em uma escuta fina para uma sociedade que também adoece e que precisa ser cuidada por nós - profissionais de saúde, professores, pesquisadores, leigos, enfim, pessoas. 


\section{REFERÊNCIAS}

1. Rosa JG. Grande sertão: veredas. Rio de Janeiro: Nova Fronteira, 2006.

2. Birman J. A psicopatologia na pós-modernidade. As alquimias no mal-estar da atualidade. Rev Lat Psicopatol Fund. [citado em 17 de nov. de 2019]. 1999; 2(1):35-49. Disponível em: https://dx.doi.org/10.1590/1415-47141999001003

3. Silveira LC, Braga VAB. Acerca do conceito de loucura e seus reflexos na assistência de saúde mental. Revista Latino-Am Enf. 2005; 13(4):591-5.

4. Amarante P. (org.) 2003. Archivos de Saúde Mental e Atenção Psicossocial. Rio de Janeiro: NAU Editora.

5. Organização Mundial de Saúde (OMS). Livro de recursos da OMS sobre a saúde mental, direitos humanos e legislação [Internet]. 2005 [citado em 17 de nov. de 2019]. Disponível em http://www.who.int/mental_health/policy/Livroderecursosrevisao_FINAL.pdf

6. Guedes CR, Nogueira MI, Camargo Jr KR. A subjetividade como anomalia: contribuições epistemológicas para a crítica do modelo biomédico. Cien S Col. 2006; 11(4):1093-103.

7. Organização Mundial de Saúde. CID 10: Classificação estatística internacional de doenças e problemas relacionados à saúde (10.rev). São Paulo: Edusp, 2014.

8. Donatelli MF. Psicodiagnóstico interventivo fenomenológico-existencial. In. S. Ancona-Lopez (org). Psicodiagnóstico interventivo: Evolução de uma prática (pp.45-64). São Paulo: Cortez, 2013.

Boa leitura!

Lilian Claúdia Ulian Junqueira

Psicóloga. Mestre e Doutora em Psicologia. Professora da Universidade Paulista, Ribeirão Preto.

Fabio Scorsolini-Comin

Psicólogo. Mestre e Doutor em Psicologia. Professor da Universidade de São Paulo (Campus Ribeirão Preto).

Editores convidados 